a nervous time ahead. Future developments at CERN will be closely watched. Will there be a British contribution for the $300 \mathrm{GeV}$ accelerator that the planners would like to contract? That is what people will be asking. If the British Government wishes to show that its behaviour over ELDO is not pure pique, it could not do better than make some clear promise about the future of CERN.

The future of rocket technology in Europe is more difficult to foresee, but some things are plain. The problems of ELDO have sprung from trying to accomplish in five years, and with small resources, developments which have taken three times as long, and which have cost enormous efforts elsewhere. There is a case for supporting modest programmes of rocket development in Europe in the decades ahead, but it is inevitable that European. countries will have to look to the United States and the U.S.S.R. for such practical applications of rocket technology as may be feasible in the decades immediately ahead. But in the short run, a capacity to launch rockets is less important than fair access to whatever the benefits of rocket technology may be. In other words, what has happened in ELDO should be a spur to the negotiations of a lasting and equitable agreement on the operation of the international system of communications satellites now being established. The existing agreement with the United States COMSAT Corporation, like the ELDO convention, will have to be renewed in 1969, and it is not too soon to begin making plans for what comes next.

\section{NO MORE MANDARINS}

T HE departure of Sir Solly Zuckerman from the post of chief scientific adviser to the British Minister of Defence is something of an occasion. For one thing, he has been there so long that he will be missed, to say the least of it. For most of the past decade his influence has been pervasive, and on the side of realism. He has helped to broaden the thinking of the defence people, and in particular has done much to expose them to the influence of academics of all kinds. He has been enlivening and stimulating. It is therefore good to know that he will not promptly disappear from Whitehall. The suggestion that Sir Solly will now concern himself with research and development on the civil side of government is particularly welcome, partly because the recommendations of the Committee on the Management and Control of Research and Development, of which he was chairman and which reported in 1961 , are still only partially digested, but also because the British Government has not yet paid as much attention to the management of its own research and development as to the scrutiny of what is done elsewhere with public money.

The days are long since gone when ministries were dependent for scientific advice on such a small number of people that each adviser became a kind of mandarin, possessed, in the eyes of politicians and soldiers, of magic such as the differential calculus, and set apart from academic colleagues by having access to classified information. Instead, quite properly, there are now arrangements for making sure that scientific advice and criticism are an integral part of planning for defence and not an afterthought. At the same time, there has been a shift of interest from technology to economics. Cost effectiveness is the order of the day, in defence ministries everywhere. That, too, is as it should be.

\section{MATHEMATICAL METEOROLOGY IN THE U.S.S.R.}

Investigation of the Bottom 300-Meter Layer of the Atmosphere

Edited by N. L. Byzova. Translated from the Russian by A. Moscona. Pp. v+112. (Jerusalem: Israel Program for Scientific Translations; London: Oldbourne Press, 1965.) 27s.

Long-Range Hydrodynamic Weather Forecasting Edited by E. N. Blinova. Translated from the Russian. Pp. iv + 124. (Jerusalem: Israel Program for Seientific Translations; London: Oldbourne Press, 1965.) $27 \mathrm{~s}$.

Objective Analysis of Meteorological Fields

By L. S. Gandin. Translated from the Russian by IPST Staff. Edited by R. Hardin. Pp.vi +242 . (Jerusalem: Israel Program for Scientifie Translations; London: Oldbourne Press, 1965.) $81 s$.

AFTER 20 years of comparative stagnation, relieved A by only a few isolated bright spots, dynamica] meteorology began to move forward soon after the end of the Second World War to become, what it can now claim to be, a coherent branch of quantitative fluid mechanics. For a number of years progress was much stimulated by close relations between American and European workers, while the work going on in Russia was unknown and ignored in the West, and it is only in quite recent years that representative literature has become available and readily accessible in translation. With still many gaps to be filled, the initiative of the Israel Program for Scientific Translation in publishing the three meteorological texts under review will be widely welcomed.

Investigation of the Bottom 300-Meter Layer of the Atmosphere is a collection of thirteen short research papers concerned with the data from a 300 -m meteorological mast. The study of the planetary boundary layer is one in which the basic theoretical contributions from the Soviet Union have been of the greatest importance, and it suffices to draw attention to this translation to ensure that all workers in the subject will give it their attention.

Long-Range Hydrodynamic Weather Forecasting is also a compilation of research papers, seven in all, providing further examples of mathematical techniques and physical concepts which, in spite of the title, were largely anticipated by Kibel's 's text-book which appeared in translation some years ago. Again, the mere notice of the work will ensure that it will be scrutinized carefully by the relatively few specialists engaged in mathematical studies of problems of meteorology on the largest scale. Special attention may, however, be drawn to a paper by M. B. Galin which attempts to set up a closed set of equations to determine certain correlation functions which emerge when the basic dynamical equations are averaged to produce relations between climatological or other timemean values. The treatment of these functions, effectively of synoptic-scale turbulence, is perhaps the most fundamental problem of fluid mechanics for which no basic solution applicable to world-scale problems is yet in sight. It is doubtful whether purely mathematical manipulation will really overcome the physical difficulty, but the attempt will be studied with interest.

The third work, Objective Analysis of Meteorological Fields, is, by contrast, a valuable monograph on a limited theme, and prompts a little digression. The post-war application of basic fluid physies to atmospheric motions of weather systems on the largest scale and to the general circulation is particularly important and interesting because of its direct relevance to routine weather forecasting, more or less familiar to everyone. The techniques in use hitherto depended on the charting of weather patterns and particularly of barometric pressure patterns drawn freehand and extrapolated into the future by expert judgment-a highly subjective process. It should 